INTERNATIONAL HIGHER EDUCATION, No. 67, Spring, 2012

Pages 7-9

\title{
New Ways to Rank Universities
}

\section{ROBERT BIRNBAUM}

Robert Birnbaum is professor emeritus of higher education, University of Maryland, College Park. E-mail: rbirnbau@umd.edu.

It is university rating time again, and the newly released 2011 reports-whether coming from China, the United Kingdom, or other venues—are producing either smug satisfaction or the gnashing of teeth at institutions around the world. Although such ranking schemes have little educational relevance, they have great symbolic, economic, and political significance. They give certain institutions and countries "bragging rights," and encourage "prestige wars." Some institutions are led to game the system by making changes that have little positive educational impact but do respond to the criteria used by the rankers. Driven by the rationalistic mantra of accountability, the notion that international ranking provides some positive benefit, while frequently asserted, has never been demonstrated. The concept itself appears to have many of the characteristics of an academic fad; it makes the ephemeral look scientific, increases activity, but leads to little substantive improvement.

To add an element of color to the otherwise drab rating exercise, several years ago I proposed five alternative ways to separate the educational sheep from the academic goats. The "sausage system" suggested combining all systems, regardless of whether they rated as the best party schools or with the most Nobel laureates, to create a single metaranking. The "Lake Wobegon 
system" proposed expanding the number of institutions that could be included in the "Top Fifty World-Class Universities," so that more of them could be considered above average. The "Jeremy Bentham system" would rank institutions, according to the level of happiness they provided. The "Olympic system" suggested that rankings be based on head-to-head competition of institutional faculty engaging in feats of physical prowess, while simultaneously engaging in scholarly work. Finally, the "Jorge Luis Borges system" posited that a list of the one true ranking already exists, requiring us only to discover it amidst a collection of similar-appearing, but flawed, lists.

\section{SOME NeW SCHEMES}

Significant progress has now been made on some of these proposals. Perhaps the greatest advance has been made in implementing the sausage system, which has recently gained purchase due to its use in analyzing public policy. As an example, the Ibrahim Index of African Governance is a widely recognized and influential means of assessing the performance of that continent's governments. The index is based on a number of sophisticated variables (89 at present). Ratings of these variables, including measurements of the extent of corruption, or the use of mobile telephones, are then combined into a single number, by which governments are put in rank order. The genius of the final index is that it is constructed by adding all the variables without weighing them, so that infant mortality rate is no more or less influential than is freedom of the press. Just as the Ibrahim Index is used by nongovernmental organizations and foundations as a guide for allocating resources, a single, unweighted summary of all institutional ratings might be used someday to identify the academic best of the 
best. The beginnings of such a possibility can already be seen in the new UMultiranking rating system, sponsored by the European Commission, which creates metrics in five areas-from teaching to knowledge transfer. Using this system, any group or institution can apply its own weights to self-selected variables, thus allowing each to determine the criteria by which it should be judged. As the Dodo in Alice in Wonderland presciently opined after the chaotic caucus race in which the participants started, stopped, and moved whenever and wherever they liked-“everybody has won, and all must have prizes." Well, why not?

The Lake Wobegon system may also now be coming into its own. While enlarging the number of high-ranking institutions is an obvious way to spread the wealth, the idea of doing so, by identifying 100 institutions as being among the top 50, may have seemed a bridge too far when it was first proposed. But this process now has been pioneered by the Academy of Motion Picture Arts and Sciences, which recently increased from 5 to 10 the number of potential nominees for annual Oscar for Best Picture. The implications of this change for university rankings are staggering; just as conceptually no limitation of the number of films that could be identified as "best" candidates, there is no limit to the number of universities that can be judged "world class." When Hollywood sets the trend, can other social institutions be far behind? And indeed, China has apparently already adopted a variant of this system. In 2007, the Ministry of Education reportedly rated over 80 percent of its institutions as "excellent." It cannot be long before all are considered above average. 


\section{Does RANKING MAKe Us Better?}

These trends should not be unexpected. Life follows art, as we know, and it is not surprising that the quest for the one true university ranking should move us in strange directions originally dismissed as outrageous. Current discussions, over which of the metrics currently in use is best, may reflect a movement toward the Borges system. To be sure, assessing a world-class ranking by using the Bentham or Olympic systems has so far not gained any noticeable traction; however, regardless of their usefulness the demand for comparative judgments appears insatiable.

The most recent support for developing world-class universities comes from the 2011 Riyadh Statement, which, while renouncing rankings and league tables, still concludes that national systems should support, among other things, universities with selective admissions and research missions. For many, if not most, national systems the emphasis on developing a world-class ranking should probably not be on research universities but on regional and local institutions, emphasizing teaching and curriculums based on social needs. The problem is that we get what we measure; encouraging many less-developed nations to direct their resources toward the establishment of world-class institutions ironically may inhibit the development of the basic educational infrastructure on which the existence and maintenance of great universities ultimately depend. World-class research institutions can come later, but only after the educational foundations on which such institutions depend have first been developed and nurtured. 